\title{
Expertise nojornalismo: considerações sobre a autoridade profissional no con-texto da desinformação impulsionada pelos algoritmos
}

Expertise in Journalism: Considerations about professional authority in the con-text of disinformation driven by algorithms

Experiencia en periodismo: consideraciones sobre la autoridad professional en el contexto de la desinformación impulsada por algoritmos

\section{Leonel AZEVEDO DE AGUIAR}

Pontifícia Universidade Católica do Rio de Janeiro - Brasil

laaguiar@uol.com.br

Cláudia Miranda RODRIGUES

Universidad de Lima - Perú

tmendoza@ulima.edu.pe

Chasqui. Revista Latinoamericana de Comunicación

$N .^{o}$ 147, agosto-noviembre 2021 (Sección Diálogo de Saberes, pp. 243-240)

ISSN 1390-1079 / e-ISSN 1390-924X

Ecuador: CIESPAL

Recibido: 11-11-202O/Aprobado: 10-07-2O21 


\title{
Resumo
}

O processo global de disseminação de desinformação e dispersão de conteúdo falso nas plataformas digitais, acirrado pela ação dos algoritmos, contribui para a erosão da credibilidade de um dos polos que integram o campo jornalístico: o polo profissional. A configuração contemporânea da ecologia das mídias, que se acentua com a descrença em relação à importância da expertise, resulta na desqualificação dos valores da cultura dos jornalistas e do jornalismo enquanto forma de conhecimento. Este artigo conduz uma reflexão sobre a erosão da autoridade profissional dos jornalistas, com respaldo em Abramson (2019), Kakutani (2018), Nichols (2017) e Schudson (2014; 2010). Discute ainda a noção de sistema perito e a relação entre objetividade e big data como indicadores da qualidade jornalística.

Palavras-chave: jornalismo, credibilidade, autoridade profissional, teorias do jornalismo, desinformação.

\begin{abstract}
The global process of disseminating disinformation and the dispersion of fake content on digital platforms, instigated by the action of algorithms, contribute to the erosion of credibility of one core area of journalism: the professional cluster. The contemporary configuration of media ecology, which is intensified by disbelief towards the importance of expertise, results in the disqualification of journalists' cultural values and journalism a form of Knowledge. This article conducts a reflection on the erosion of the professional authority, supported by authors such as Abramson (2019), Kakutani (2018), Nichols (2017) and Schudson (2014; 2010). It also discusses, diversely, the notion of an expert system and the relationship between objectivity and big data as indicators of journalistic quality in a scenario in which most Internet users consume information that is perceived as reliable and credible.
\end{abstract}

Keywords: journalism, credibility, professional authority, theories of journalism, misinformation.

\section{Resumen}

El proceso global de difusión de desinformación y dispersión de contenidos falsos en plataformas digitales, dificultado por la acción de los algoritmos, contribuye a la erosión de la credibilidad de uno de los hubs que integran el campo periodístico: el hub profesional. La configuración contemporánea de la ecología de los medios, acentuada por la incredulidad con relación a la importancia del saber hacer, desemboca en la descalificación de los valores de la cultura de los periodistas y del periodismo como forma de conocimiento. Este artículo realiza una reflexión sobre la erosión de la autoridad profesional de los periodistas, apoyada por Abramson (2019), Kakutani (2018), Nichols (2017) y Schudson (2014; 2010). También se discute, por el contrario, la noción de sistema experto y la relación entre objetividad y big data como indicadores de calidad periodística 
en un escenario en que la mayoría de los internautas consumen información percibida como fiable y creíble.

Palabras clave: periodismo, credibilidad, autoridad profesional, teorías del periodismo, desinformación.

\section{Introdução}

A noção do jornalismo como uma forma de conhecimento sustenta-se no seu caráter de mediação entre público e realidade. O jornalista não cria ficção; sua função é informar sobre o que é relevante em sociedade e acerca do presente momentâneo (Groth, 2015). A objetividade, regra essencial na base desta premissa (Kovach \& Rosenstiel, 2003; Guerra, 1998), permite a elaboração de uma "verdade como correspondência" (Sponholz, 2009, p. 19). A outorga concedida aos jornalistas profissionais para produzir relatos verdadeiros se assenta na expertise baseada em estratégias adotadas na produção da notícia (Tuchman, 1999; Schudson, 2010).

$\mathrm{O}$ crescimento de uma postura cética frente aos especialistas sugere que muitos cidadãos, hoje, rejeitam a mediação, seja ela de cientistas ou dejornalistas (Nichols, 2017). Essa atitude - reforçada pelo movimento negacionistaengloba ciência, história e os fatos. A fragmentação imposta ao campo do jornalismo pelo advento das plataformas digitais propiciou a disseminação de desinformação que é impulsionada por algoritmos em compartilhamentos de conteúdo escolhido, ou forjado, como verdadeiro.

O comentário do senador americano Daniel Patrick Moynihan aponta uma tendência: "todo mundo tem o direito de ter suas próprias opiniões, mas não seus próprios fatos" (Kakutani, 2018, p. 16). Em tempos de "fatos alternativos", o descaso em relação à verdade enfraquece a razão e acirra o despreza ao conhecimento especializado. Merrit e McCombs (2004) percebem o impacto da internet sobre a perspectiva histórica do jornalismo como um catalisador da deliberação democrática.

Qualquer pessoa com acesso a um modem de computador [...] não é mais apenas um destinatário de informações, mas também é um provedor de informações em potencial [...], aumentando exponencialmente a origem das informações. Quando qualquer pessoa na Terra pode teoricamente alcançar qualquer outra pessoa na Terra com qualquer mensagem - seja ela benigna, precisa ou totalmente imprecisa, difamatória ou inócua, profana ou espiritual — o problema de fornecer relevância para o processo deliberativo democrático torna-se profundo. (Merrit \& McCombs, 2004, p. 6)

Ondas de populismo e fundamentalismo espraiadas pelo mundo suscitam a aderência à sabedoria das multidões no lugar da informação especializada (Kakutani, 2018, p. 12). O Reuters Institute Digital News Report 2019 aponta como a acentuada polarização e a agenda partidária nas redes sociais contribuem 
para minar a confiança na mídia. O estudo do Reuters Institute demonstra que, mesmo com a maior adesão ao Instragram e ao Whatsapp, o Facebook se mantém como a rede social mais importante na distribuição de notícias. No dia 08/o7/2020, o Facebook bloqueou 88 contas responsáveis por disseminar fake news, impulsionadas por funcionários da presidência brasileira e de gabinetes de Flávio e Eduardo Bolsonaro, filhos do presidente Jair Bolsonaro. ${ }^{\circledR}$

O consumo de notícias de forma customizada - incluindo boatos e relatos falsos - impacta a centralidade da mídia como fonte de informação. O presidente dos Estados Unidos, Donald Trump, possui um canal de notícias no Facebook seguido por seus apoiadores - e rotula de fake news "o jornalismo que considera ameaçador ou desfavorável" ao seu governo (Kakutani, 2018, p. 117). Da mesma forma, o presidente brasileiro, Jair Bolsonaro utiliza página no Facebook para pronunciamentos oficiais e sugere blogs favoráveis ao seu governo como fonte de informação aos seus eleitores.

Há um inegável abalo na credibilidade da mídia apontado em estudos recentes $^{2}$ como o que auferiu a confiança na mídia, nos Estados Unidos, junto a millenials, população urbana e dos subúrbios, de áreas rurais, geração X e baby boomers. $\mathrm{O}$ resultado mostra o crescimento vertiginoso da desconfiança em todas as categorias. O relatório da Reuters de 2018 já apontava que apenas 50\% dos leitores confiam nas notícias veiculadas em plataformas digitais.

Atentas à conjuntura desfavorável, as organizações midiáticas buscam saídas para a "crise". O consórcio Comprova ${ }^{3}$ é um exemplo. Outro exemplo é a Global Alliance for Responsible Media, ${ }^{4}$ uma iniciativa criada recentemente que reúne imprensa, anunciantes, Google e Facebook. Apesar da descrença de parte das corporações midiáticas, o objetivo é combater o discurso de ódio e a desinformação, propondo um chamado público por mais responsabilidade coletiva nas práticas da mídia e redes sociais com cobrança de ações efetivas e accountability.

Organizado em duas seções, o artigo discute as razões pelas quais cresce o ceticismo em relação aos experts, com foco no jornalismo profissional. A partir

1 Disponivel em https://blogs.oglobo.globo.com/sonar-a-escuta-das-redes/post/facebook-derruba-rede-de-paginas-coordenada-por-funcionarios-da-presidencia-e-dos-gabinetes-de-flavio-e-eduardo-bolsonaro.html. Acesso em 10 jul. 2020.

2 A pesquisa realizada pela Reuters/Ipsos de $7 / 12 / 2018$ a 20/12/2018 ouviu 4.210 adultos, sendo 1.657 democratas e 1.505 republicanos. Disponivel em https://www.cjr.org/special_report/how-does-journalism-happen-poll.php. Acesso em 25 mar. 2019.

3 O consórcio Comprova é uma coalizão de 24 veículos de comunicação que faz debunking de fake news como o boato falso Partido dos Trabalhadores (PT) o fornecimento, em creches, de mamadeiras com bico de borracha em formato de pênis que viralizou na campanha eleitoral de 2018. A agência de fact checking Aos Fatos veiculou a checagem do consórcio Comprova no dia 28 de setembro de 2018, antes das eleições. Disponível em https://aosfatos.org/noticias/mamadeiras-eroticas-nao-foram-distribuidas-em-creches-pelo-pt/. Acesso em 16 de jun. 2019.

4 Disponivel em https://www.campaignlive.com/article/global-alliance-responsible-media-launches-fight-digital-safety/1587837?utm_source $=$ Pew +Research+Center\&utm_source $=$ Daily+Lab+emai I+list\&utm_campaign=7b0e5a900c-dailylabemail3\&utm_medium=email\&utm_term=0_d68264f d5e-7b0e5a900c-396243217. Acesso em 20 jun. 2019. 
da reflexão sobre a descrença no valor da perícia, o artigo busca compreender a construção da ideia de expertise profissional. Neste percurso, evoca uma genealogia histórica que mostra o influxo das ciências sociais sobre as rotinas jornalísticas desde a era da informação, no século XIX, até o jornalismo do big data no século XXI (Schudson, 2010; Anderson, 2018) como estratégia para construção de narrativas precisas e objetivas.

\section{Expertise em declínio}

Thabo Mbeki, presidente da África do Sul de 1999 até 2008, rejeitou a oferta de drogas para tratamento de portadores de Aids porque acreditava que a infecção era resultado de fatores como sujeira e desnutrição. Médicos da Harvard School of Public Health calculam que a negação foi responsável por mais de três mil mortes e o nascimento de 35 mil crianças portadoras de HIV. Thabo era seguidor de um grupo de pesquisadores que, contra todas as evidências empíricas que comprovaram a existência do vírus da imunodeficiência humana (HIV), negava fatos científicos (Nichols, 2017, p. 1-3).

Em obra lançada em 1962, Richard Hofstadter já notava a forma como a complexidade do mundo moderno fez brotar um sentimento de pouca competência e autonomia junto ao cidadão comum. Esse complexo de opressão produziu sentimento de desamparo e rancor junto a um segmento que se sentiu subjugado e transformou o conhecimento formal em razão de ressentimento. Se antes o expert era considerado essencial, agora ele é rechaçado por ocupar o lugar de cidadão crucial. "O problema aumenta quando as pessoas começam a acreditar que conhecer um pouco sobre algo significa perícia” (Nichols, 2017, p. 37).

Trump e Bolsonaro desprezam o conhecimento especializado e sistematicamente desqualificam a mídia. Para Kakutani (2018, p. 33-34), é um reflexo do declínio da importância do discurso racional e do bom senso, tendência apontada previamente por autores como Susan Jacoby. Entre as causas, um vício no infoentretenimento, a força do fundamentalismo religioso, a associação do intelectualismo ao liberalismo em desacordo com valores tradicionais americanos e um sistema educacional que não fornece habilidades básicas e, consequentemente, "lógicas para reger estas habilidades" (Jacoby, 2008, p. 307).

Kakutani argumenta que o pós-modernismo tem forte influência sob a queda da confiança nas instituições. O relativismo que ganhou força na década de 1960 desencadeou um processo crítico em relação às narrativas oficiais e relativizou o conceito de verdade. Mas longe de culpar os pós-modernistas pelo niilismo que se aprofunda, Kakutani (2018, p. 53) percebe como os setores políticos organizados da direita se apropriaram desta narrativa.

A credibilidade da mídia também foi impactada por críticas ao viés ideológico e influência no processo político em países como Rússia, Venezuela 
e Peru (Levitsky \& Ziblatt, 2018). Neste último, no final dos anos 1990, toda a rede de televisão e vários jornais tabloides constavam na folha de pagamento do governo e o principal acionista do Canal 5 recebeu 50 mil dólares em troca da demissão de dois repórteres investigativos (ibidem, p. 85). Abramson (2018), em "Merchants of Truth, observa como a controversa abertura da guerra do Iraque, por exemplo, abalou a reputação sobre a autoridade da imprensa americana. Questionamentos ideológicos sobre as imbricações políticas da atividade jornalística cresceram a partir dos anos 1960 e resultaram uma série de investigações acadêmicas (Traquina, 2012, p.162). Esta cultura crítica abalou conceitos cristalizados, como a objetividade da mídia jornalística.

A crença na capacidade de o sistema midiático exercer interferência na seleção e circulação de informações e de interpretações que ajudam a consolidar a construção de consensos sociais é a base das teorias da ação política (Traquina, 2012). Este pensamento encontra eco em autores como Herman e Chomsky (2002), Stuart Hall (1973), Gítlin (1964), Moraes (2013) e Ramonet (2013).

A esmagadora variedade de fontes nas plataformas digitais favorece ainda a busca por conteúdo que confirme opiniões ou corrobore fatos. Kavanagh e Rich (2018) notam que as mídias sociais facilitam que a audiência compartilhe as mesmas crenças, o que prejudica a exposição e aceitação de informações fidedignas. Esta realidade alimenta a polarização e as bolhas na internet e, em última análise, intensifica a disseminação de desinformação. As mídias partidárias - onde predomina a indefinição entre opinião e fatos e a ideia de "agente da Verdade" - estimulam a crescente desconfiança na mídia (Kavanagh \& Rich, 2018, p. 96). O Jornal da Cidade Online — denunciado por veicular conteúdo falso - é um exemplo de esgarçamento entre material factual e opinativo ${ }^{5}$ com excesso de adjetivos e viés ideológico.

Com respaldo em Tocqueville, Nichols (2017) assinala o vínculo entre a desconstrução da confiança na autoridade intelectual e a ideia da igualdade na América. A premissa igualitária leva os cidadãos a buscar em sua própria razão a fonte mais óbvia e próxima da verdade. Neste sentido, a disposição de confiar na autoridade, seja ela qual for, enfrentará resistência.

Nichols (2017) localiza o processo de erosão da confiança na mídia, nos Estados Unidos, a um fenômeno observado desde os anos 70 a partir da influência de talk shows em rádios $\mathrm{AM},{ }^{6}$ como o do apresentador Rush Limbaugh, com

5 A CPMI das Fakes News do Senado identificou dois milhões de anúncios da Secretária de Comunicação da Presidência do governo Bolsonaro em sites que publicam notícias falsas, entre eles, o Jornal da Cidade Online. O projeto de lei 2.630/2020, aprovado no dia 30/06/2020, foi batizado de Lei das Fake News e visa responsabilizar as redes sociais pela divulgação de notícias falsas e proibir contas que são, na realidade, robôs manipulados por organizações criminosas e impulsionados com ajuda de algoritmos. O Supremo Tribunal Federal prossegue investigações sobre notícias fraudulentas iniciadas em março de 2019 que ficou conhecido como "inquérito das fake news" e foi prorrogado por mais seis meses, em junho de 2020 A diligência - que motivou a elaboração do projeto de lei das "fake news" - levantou que 12 perfis nas redes sociais disseminam conteúdo falso sobre ministros do STF.

6 Nos Estados Unidos, somente depois de 1978 as rádios FM alcançaram mais ouvintes que as rádios AM (Nichols, 2017, p. 145). 
penetração em seiscentas estações em todo o país. O autor de Death of Expertise nota como Limbaugh torna-se fonte de verdade frente ao resto da mídia americana. $O$ jornalista e acadêmico sustenta que a repercussão do talk radio "forneceu a fundação para os ataques ao conhecimento estabelecido que mais tarde floresceram nas mídias sociais" (Nichols, 2017, p. 145). ${ }^{7} \mathrm{O}$ debate inclusivo era apenas o pretexto para que o apresentador criasse um agenciamento e um senso de comunidade entre pessoas inclinadas a concordar entre si. Este modal foi pioneiro na construção de redes sociais e conexão entre pessoas que rejeitavam a grande mídia e posteriormente seria ultrapassado pela internet em seu poder de conectividade.

A ascensão do rádio desafiou o papel dos especialistas, reforçando a crença popular que os meios de comunicação estabelecidos foram desonestos ou pouco confiáveis. Locutores de radio não só atacavam crenças políticas consolidadas. Atacavam tudo, mergulhando seus ouvintes em um universo alternativo onde fatos de qualquer tipo não eram credíveis a menos que verificados pelo apresentador. Em 2011, Limbaugh denominava governo, universidades, ciência e mídia os 'quatro pilares da enganação'. (Nichols, 2017, p. 147)

Um exemplo da influência de figuras midiáticas nas redes sociais é o caso da jornalista curitibana Joice Hasselman. Durante a campanha eleitoral de 2018, Hasselman lançou, no You Tube, seu próprio canal de notícias, o JHN (Joice Hasselman News). A atuação nas redes começou quando era candidata à deputada estadual pelo PSL. Sem provas, a jornalista publicou vídeo, em 24 de setembro de 2018, denunciando que "uma grande revista" teria recebido $\mathrm{R} \$ 600$ milhões para "destruir Jair Messias Bolsonaro".

Revivificado na era da pós-verdade, George Orwell (1981), ao analisar a guerra civil espanhola em texto originalmente publicado em 1943, reflete sobre o surgimento de lideranças messiânicas quando a verdade se apresenta fragmentada. $\mathrm{O}$ autor observa como o nazismo negava a existência da verdade com o objetivo nefasto de controlar não apenas o futuro, mas também o passado. O precedente perigoso, nos alerta Orwell, é que se o líder diz que um fato nunca aconteceu, de fato nunca aconteceu.

\section{Autoridade profissional, objetividade e dados}

Conhecimento específico é algo inerente em qualquer ocupação. As palavras profissional, intelectual e expert são intercambiáveis em um sentido amplo e referem-se às pessoas com habilidades particulares e atuação em áreas específicas. Experts aprimoram experiência e competência continuamente e aprendem com seus erros. São pessoas com domínio sobre um assunto, ou seja,

7 Traduzido do original: Talk radio had an immense political consequences, and it provided the foundantion for attacks on established knowledge that flowered later on social media.

8 Disponivel em https://www.youtube.com/watch?v=rg00MYQjFrs. Acesso em 15 dez 2019. 
"as informações que eles fornecem ao resto das pessoas são verdadeiras e podem ser confiáveis" (Nichols, 2017, p. 33).

Estratégias, como peer review, a ação de instituições como conselhos regionais e normas estabelecidas por estatutos, códigos de ética e ombudsmen asseguram a competência (Nichols, 2017, p. 35). Tais expedientes reforçam o controle de qualidade e ajudam a manter a confiança nos especialistas, em cada uma de suas áreas específicas. Estes protocolos explicam a responsabilidade que recai sobre profissionais que emitem laudos e/ou licenças e suas repercussões em caso, por exemplo, de ocorrência de acidentes.

A credibilidade está enraizada nas noções de competência, denominada também autoridade - que dá conta do conhecimento técnico sobre o assunto abordado - e na integridade da fonte, que engloba compromisso com a verdade e reputação (Lisboa, 2012). Esta perspectiva remete ao conceito de sistemas peritos desenvolvido por Giddens (1991) a fim de explicar mecanismos presentes na sociedade contemporânea marcada pela reestruturação das relações sociais. Segundo o sociólogo britânico, são sistemas de competência técnica ou profissional que organizam o mundo atual. Quando sobe uma escada de uma moradia, o indivíduo confia no conhecimento técnico de um engenheiro civil e de um arquiteto.

Quando o leitor ou espectador confia na informação veiculada pela mídia seja ela impressa, online ou televisiva - deposita sua credibilidade porque tem fé na perícia e precisão que supõe ser aplicada na produção da notícia. Miguel (1999) se apoia no conceito de Giddens para expor a forma como o jornalismo pode ser considerado um sistema perito no que tange o campo da produção de notícias. A confiança do leitor/ouvinte/espectador se explicita na confiança quanto à veracidade das informações relatadas, em face do rigor na seleção e hierarquização dos elementos importantes no relato e na recolha correta das notícias diante do manancial de fatos disponíveis (Miguel, 1999, p. 187). Compreender o sentido epistemológico do conceito de objetividade jornalística parece, portanto, ser fundamental.

Enquanto gastam mais tempo tentando sintetizar a enorme massa de informação que tiram dos portais da internet, os jornalistas correm o risco de se tornarem mais passivos, recebendo mais do que procurando saber. Para ajudar a combater esse risco só existe um caminho: um melhor entendimento do significado original de objetividade, que daria maior solidez à informação. (Kovach \& Rosenstiel, 2003, p. 120)

Neste sentido, Kovach e Rosenstiel (2003) ponderam que isenção e equilíbrio funcionam como técnicas e recursos mais do que como valores. Da mesma forma, a objetividade enquanto método contribui para que os jornalistas possam construir caminhos para verificação de seus relatos. $\mathrm{O}$ valor destes métodos profissionais não pode ser visto como fachada ou objetivo. "Seu valor 
reside em ajudar-nos a chegar mais perto de uma verificação autêntica e uma versão confiável dos fatos" (Kovach \& Rosenstiel, 2003, p. 116). Portanto aqueles

Que selecionam as fontes para expressar o que na verdade é seu próprio ponto de vista, e depois usam uma voz neutra para que tudo pareça bem objetivo, estão trapaceando. Isso prejudica a credibilidade da profissão ao fazê-la parecer sem princípios, desonesta e preconceituosa. (Kovach \& Rosenstiel, 2003, p. 117)

Ao estabelecer seu código de ética, ou os Cânones do Jornalismo, a American Society of Newspaper Editors, criadas por editores dejornais americanos em 192223, incluiu como princípios "Sinceridade, verdade e precisão" e imparcialidade (Schudson, 2014, p. 152). Foi nesta época que a palavra objetividade começou a ser utilizada e seu significado era alcançar a verdade através do método científico a partir de procedimentos rigorosos (Streckfuss citado por Sponholz, 2009, p. 61). O conceito foi fundado a partir da percepção que o ser humano não pode ser objetivo o que impõe a necessidade de estratégias e rituais (Tuchman, 1999).

Na segunda metade do século XIX, a "objetividade" dos fatos dominou profissões como medicina, sociologia e economia e marcou ojornalismo a partir das noções objetivas do empirismo, da coleta de dados e do próprio método científico (Sponholz, 2009). Esta visão tem sua origem na era do Positivismo quando muitos repórteres buscavam treinamento em disciplinas científicas e a reportagem enfatizava a observação e a factualidade em detrimento do comentário discursivo (Schudson, 2014). Schudson (2010) pondera que este conceito estava atrelado à "expressão da cultura de uma sociedade democrática de mercado que passava por transformações urbanas" (Schudson, 2010, p.93-94). A separação entre fatos e valores foi adotada a partir de um senso profissional crescente, nas primeiras décadas do século XX, que identificava o jornalista como parte de um grupo com modus operandi próprio (Schudson, 2014, p. 150). Neste momento, os repórteres americanos aderem ao "uso indiscriminado e inteligente das anotações”, prática que tornou a entrevista uma técnica de uso cotidiano na produção da informação jornalística.

A entrevista — que era tudo menos desconhecida em 1865 - foi largamente praticada por volta de 1900 e se tornou o pilar do jornalismo americano na época da Primeira Guerra Mundial, quando ainda era rara na Europa. A rápida difusão dessa nova prática entre os jornalistas americanos parece não ter sido acompanhada por nenhum argumento ideológico. Encaixa-se facilmente em um jornalismo centrado no fato e na notícia, ao invés de principalmente dedicado ao comentário político ou preocupado com aspirações literárias. (Schudson, 2014, p. 157)

Anderson (2018) observa a ausência de fronteiras entre quase-profissões como jornalistas e cientistas sociais no final do XIX e começo do século XX. Schudson (2010) destaca como a investigação social sistemática tornou-se quase um modismo e observar era um fator sine qua non para os repórteres nos Estados 
Unidos. Nesta época começa a se consolidar a compreensão da objetividade como um suporte para a verificação de fatos. Era frequente a adoção das pesquisas de campo por sociólogos que abraçaram as rotinas de trabalho jornalísticas de forma explícita ou implícita (Anderson, 2018, p. 17).

Através de um percurso metodológico de inspiração foucaultiana, Anderson (2018) propõe uma genealogia que constrói uma ponte entre o passado, influenciado por uma visão positivista, e o presente onde se consolida o jornalismo de dados. Em outras palavras, se este termo é algo contemporâneo, o uso de dados no jornalismo remonta o final do século XIX e, em diferentes momentos, está atrelado à tentativa de construir narrativas verdadeiras. Portanto, a relação entre jornalismo e dados está fundada em um modo normativo e genealógico, "sua proposta e seu uso é acionada dentro de um emaranhado percurso histórico" (Anderson, 2018, p. 5). A cultura da verdade que rege o campo jornalístico - foi impactada pelo trabalho social no momento em que a Sociologia estabeleceu seus métodos.

A relação complexa entre os dois campos - jornalismo e as ciências sociais - é essencial para a compreensão do uso da informação quantitativa em três momentos-chave que se constituem eras político-sociais. Propomos que a primeira clivagem orientada pelos dados é estabelecida no final do século XIX, quando editores exigem evidências com impacto nas práticas jornalísticas (Schudson, 2010; Anderson, 2018). O segundo momento está centrado na década 6o, quando foi cunhado o termo "jornalismo de precisão", por Philip Meyer. A confiança profissional revigorada levou jornalistas a atuarem como "cientistas sociais" (Anderson, 2018, p. 2).

A busca por uma apuração acurada e confiável foi a fonte de inspiração, na década de 70, para o repórter e professor Philip Meyer - autor do manual Jornalismo de Precisão - sistematizar uma metodologia quantitativa conhecida como CAR (Reportagem Assistida por Computador), conceito-chave precursor do big data (Howard, 2014). Meyer salienta que, diante de fontes menos confiáveis, os jornalistas devem apreciar os benefícios do jornalismo de dados.

Os adeptos do CAR tem procurado - — seja conscientemente ou não— um padrão mais elevado de verdade. Nossa resposta à era da informação tem sido aprender a gerenciar um corpo maior de dados com ferramentas analíticas cada vez mais ponderosas, levando a uma definição exata da verdade. Quando isso acontece, um computador é útil [...]. Mas o computador em si não é o objetivo, nem define o que estamos tentando fazer. Estamos tentando empurrar o jornalismo em direção à ciência. (Meyer, 2005, n/a)

Observamos a definição do terceiro momento com a atuação dos jornalistas de dados capazes de trabalhar uma nova tessitura narrativa que envolve recursos multimídias, com gráficos desenvolvidos dentro da semântica do jornalismo digital. Este desenvolvimento "marca ainda mais a transformação da objetividade jornalística e das ferramentas disponíveis para o jornalismo 
contar histórias de uma maneira nova” (Anderson, 2018, p. 3). Se a metodologia do jornalismo de dados serve de antídoto contra a produção jornalística de credibilidade questionável, a "objetividade" é garantida pela abundância de informações na web (Charbonneaux \& Gkouskou-Giannakou, 2015, p. 275).

Anderson (2018) pesquisou a atuação de movimentos religiosos fundados no século XIX, inspirados por práticas jornalísticas e pela aderência ao social survey reportage (a reportagem com cunho social). O fenômeno, explica o historiador, revela a predominância de certezas epistemológicas: a crença na relevância de evidências empíricas colhidas no campo e a obsessão pelo poder dos números em iluminar importantes verdades. $O$ método de coleta de dados e estatísticas se constituiu em uma lente própria que permitia a compreensão da sociedade. Ao realizar um estudo de caso documental sobre a SSM (Society of Sacred Mission), Anderson (2018) inferiu como o movimento religioso, fundado em 1893, procurou publicizar dados com objetivo de conquistar mais credibilidade. O SSM acreditava, desta forma, ser possível instigar reformas sociais.

A proximidade e o distanciamento desta época para o tempo atual é compreensível quando consideramos que o SSM foi constituído por um grupo de homens e mulheres que partilhavam a crença de que a praga da pobreza e da revolta social poderiam ser amenizadas a partir de simples coleta de dados estatísticos granulares sobre as condições sociais urbanas existentes. Em 1911, pouco desta informação (...) era acessível. Na atual era do big data, o espírito desta distribuição estatística reverbera junto ao cidadão conectado em rede. (Anderson, 2018, p. 20)

Kavanagh e Rich (2018) reforçam que, em tempos de desinformação, informações corretas baseadas em gráficos, ilustrações e dados abertos se adequam a altos padrões de qualidade. O acesso a dados promovido por agências como a brasileira Gênero e Número e britânica The Bureau of Investigative Journalism promovem transparência e servem como contraponto ao descrédito que cresce em ambientes polarizados e dominados por viés político. $\mathrm{O}$ acesso às informações governamentais com a criação de portais de transparência favoreceu a cultura do big data. A reportagem Panamá Papers denúncia sobre envolvimento de figuras públicas e empresas no esquema de paraísos fiscais no exterior conduzido pelo ICIJ (Consórcio Internacional de Jornalismo Investigativo) - foi um marco que mostrou o potencial da combinação entre dados abertos, objetividade, autoridade profissional e relevância jornalística.

A fim de trazer transparência para as contas e investimentos da União Europeia, a agência britânica The Bureau of Investigative Journalism, em parceria com o jornal Financial Times, lançou um banco de dados abrangente que permitia acompanhar cada centavo distribuído pelos fundos estruturais da EU. ${ }^{9}$ Jornalista investigativa do FT, Cinthia O'Murchu — que integrou a equipe-

9 Disponivel em https://www.thebureauinvestigates.com/stories/2010-11-29/eus-hidden-billions. Acesso em 26 set. 2019. 
reforça o uso do big data como ferramenta para realização de reportagem com precisão na apuração.

O exercício não deve ser apenas analisar e visualizar dados mas usá-los como ferramenta para se aproximar da verdade do que está acontecendo no mundo. Eu vejo a capacidade de poder analisar e interpretar dados como uma parte essencial do kit de ferramentas dos jornalistas de hoje. [...] Em última análise, o que importa é a boa reportagem, é contar história da maneira mais apropriada. (Gray et al., 2012, p. 18)

Se o tensionamento no campo jornalístico é evidente, como refletem Franciscato e Guerra (2006), é necessário atualizar a prática profissional. Os autores refletem sobre a própria questão da autoridade profissional, das normas e preceitos éticos, que traz em seu âmago o questionamento sobre a capacidade da mídia oferecer relatos verdadeiros a partir de procedimentos de investigação objetiva. Os autores apontam especificidades como a efemeridade e a necessidade de atualização permanente da notícia que levam a uma simplificação no método de coleta de dados em comparação com o rigor científico. Franciscato e Guerra (2006, p. 95) assinalam que adotar um nível intermediário entre as ciências e o senso comum possibilita ao jornalismo recorrer a métodos, práticas e formas que não incorram na perda de sua especialidade.

Autores que se debruçam sobre a aplicação do big data (Hermida \& Young, 2019; Anderson, 2018; Lawrence \& Suddaby, 2006; Lowrey, 2013; Lewis, 2013; Howard, 2014; Parasie 2015; Charbonneaux \& Gkouskou-Giannakou, 2015) sugerem que a emergência do jornalista de dados - com sua expertise e pensamento computacional - fortalece a autoridade profissional e contribuiu para a regeneração do campo do jornalismo.

\section{Considerações finais}

O percurso deste artigo parte de uma panorâmica sobre a conjuntura do jornalismo em tempos de crescente processo de desinformação. Estudos recentes mostram como a credibilidade e centralidade da mídia sofreram impacto. "Notícias" falsas geram mais engajamento do que conteúdo produzido pelas grandes organizações jornalísticas e midiáticas em um cenário onde a polarização e a agenda partidária nas redes sociais arranham a confiança no trabalho jornalístico. Os eco chambers - ou as bolhas- escolhem suas informações em um processo de consumo customizado onde rechaçam conteúdo que não confirma suas crenças.

A fim de compreender as razões para o perceptível declínio da expertise, e consequentemente, da ideia de autoridade profissional, buscamos respaldo em autores como Nichols (2017), Kakutani (2017) e Abransom (2018) que buscam respostas no passado recente e no cenário contemporâneo. A percepção de um viés ideológico adotado pela mídia é um dos fatores que contribuem neste 
processo. O pós-modernismo e o relativismo corroboram a ideia de fatos socialmente construídos, relativizando a noção de verdade e acentuando a queda da confiança nos experts e em diretrizes como a objetividade.

A construção do lugar da autoridade está atrelada ao valor da competência e do conhecimento perito, binômio que corrobora a credibilidade e a confiança. A perícia na produção de uma notícia eleva seu grau de confiabilidade. Sem ignorar a complexidade da discussão teórica em torno da objetividade, introduzimos esse conceito no que tange a questão do método e do rigor profissional, um caminho para verificação e construção de relatos verdadeiros.

A partir de uma abordagem genealógica, autores como Anderson (2018), Schudson (2014) e Meyer (2002) percebem a correlação estreita entre ciências sociais e jornalismo, sob a influência de uma cultura da verdade e da coleta de dados. A objetividade — que marcou o jornalismo na virada do século XIX para o século XX - se reveste de significado metodológico cientifico com o objetivo de enunciar a verdade a partir de procedimentos rigorosos. Nesta direção, o jornalismo de precisão de Meyer procurou criar um método de apuração acurada.

O uso de dados - que atravessa um percurso histórico - se constitui, portanto, em estratégia para construção de narrativas credíveis. Fransciscato e Guerra (2006) argumentam que encontrar um hibridismo entre as ciências e o senso comum amplia os recursos do jornalismo, com uso de práticas que não comprometem sua natureza. Dentro desta perspectiva, autores como Hermida e Young (2019), Anderson (2018), Howard (2014) e Lewis (2013) acreditam que a emergência do jornalismo de dados ajuda a revigorar a autoridade profissional e, em última análise, o próprio campo jornalístico.

\section{Referências bibliográficas}

Abramson, Jill (2019). Merchants of Truth: the business of news and the fight for facts. New York: Simon \& Schuster.

Anderson, Chris W. (2018). Apostles of certainty. Data Journalism and politics of doubt. Oxford: Oxford University Press.

Charbonneaux, Juliette, \& Gkouskou-Giannakou, Pergia (2015). O jornalismo de "dados", uma prática de investigação? Um olhar sobre os casos alemão e grego. Brazilian Journalism Research, 2(11), 266-291.

Franciscato, Carlos Eduardo \& Guerra, Josenildo (2006). Contributions of qualitative research to journalistic reporting. Brazilian Journalism Research, 2(2), 83-97.

Giddens, Anthony (1990). As consequências da modernidade. São Paulo: Ed. Unesp.

Gitlin, Todd (1964). News is what newspapermen make it. Em Antony Dexter Lewis, \& David White (Eds.), People, society and mass communications (p. 172-182). New York: Free Press.

Gray, J., Bounegru, l., \& Chambers, L. (2012). The Data Journalism Handbook. Sebastopol: O'Reilly Media.

Groth, Otto (2011). O poder cultural desconhecido: fundamentos da Ciência dos Jornais. Petropólis: Vozes. 
Guerra, Josenildo (1998). A objetividade nojornalismo. (Dissertação de mestrado). Faculdade de Comunicação, Universidade Federal da Bahia.

Hall, Stuart et al. (1973). The Social Production of News: mugging in the media. Em Stanley Cohen, \& Jock Young (Eds.), The Manufacture of News (p. 224-248). Beverly Hills, Ca: Sage Publications.

Herman, E. S., \& Chomsky, N. (2002). Manufacturing Consent. New York: Pantheon Books.

Hermida, Alfred, \& Young, Mary Lynn (2019). Data Journalism and the Regeneration of News. New York: Routledge.

Howard, B. (2014). The Art and Science of Data-Driven Journalism. New York: Columbia Journalism School.

Hofstadter, Richard (1962). Anti-Intellectualism in American Life. New York: Vintage Books. Jacoby, Susan (2008). The Age of American Unreason. New York: Pantheon Books.

Kakutani, Michiko (2018). A morte da verdade. Rio de Janeiro: Intrínseca.

Kavanagh, Jennifer, \& Rich, Michael (2018). Truth Decay: An Initial Exploration of the Diminishing Role of Facts and Analysis in American Public Life. Santa Monica: Rand Corporation.

Kovach, Bill, \& Rosenstiel, Tom (2003). Os elementos do jornalismo: o que os jornalistas devem saber e o público exigir. São Paulo: Geração Editorial.

Levitsky, S. \& Ziblat, D. (2018). Como as democracias morrem. Rio de Janeiro: Zahar. Lewis, Seth C. (2015). Journalism In An Era Of Big Data. Digital Journalism, 3(3), 321-330.

Lisboa, Silvia (2012). Jornalismo e a credibilidade percebida pelo leitor: independência, imparcialidade, honestidade, objetividade e coerência. (Dissertação de Mestrado em Comunicação). Universidade Federal do Rio Grande do Sul.

Meyer, Philip (2002). Precision Journalism: A reporter's Introduction to Social Science Methods. Maryland: Rowman \& Littefield.

Merritt, Davis, \& McCombs Maxwell (2004). The Two W's of Journalism: The Why and What of Public Affairs Reporting. Mahwah, NJ: Lawrence Erlbaum Associates.

Miguel, Luiz Felipe (1999). O jornalismo como sistema perito. Tempo Social, 11(1), 197-208.

Moraes, D. (2013). Agências alternativas em rede e democratização da informação na América Latina. Em D. Moraes et al. (Eds.), Mídia, poder e contrapoder. Da concentração monopólica à democratização da informação. São Paulo: Boitempo Editorial.

Nichols, Thomas (2017). The death of expertise. The Campaign Against Established Knowledge And Why It Matters. New York: Oxford University Press.

Orwell, George (1981). Looking Back on the Spanish War. A Collection of Essays. New York: Houghton Mifflin Harcourt.

Parasie, Sylvain (2015). Data-Driven Revelation? Epistemological tensions in investigative journalism in the age of big data. Digital Journalism, 3(3), 364-380.

Schudson, Michael (2014). A norma da objetividade no jornalismo Americano. Em Igor Sacramento, \& Letícia Matheus Cantarela (Eds.), História da Comunicação. Rio de Janeiro: Mauad.

Schudson, Michael (2010). Descobrindo a notícia: uma história social dos jornais nos Estados Unidos. Petrópolis: Vozes.

Sponholz, Liriam (2009). Jornalismo, conhecimento e objetividade: além do espelho e das construções. Florianópolis: Insular.

Traquina, N. (2012). Teorias do Jornalismo. Por que as notícias são como são. Florianópolis: Insular. 
EXPERTISE NO JORNALISMO: CONSIDERAÇÕES SOBRE A AUTORIDADE PROFISSIONAL NO CON-TEXTO...

Tuchman, Gaye (1999). A objectividade como ritual estratégico: uma análise das noções de objectividade dos jornalistas. Em Nelson Traquina (Ed.), Jornalismo: questões, teorias e "estórias". Lisboa: Vega. 
